\title{
Gloria Bautista Gutiérrez REALISMO MÁGICO, COSMOS LATINOAMERICANO TEORÍA Y PRÁCTICA Editorial América Latina, Santafé de Bogotá, D.C., edición noviembre 1991, p. 141
}

La autora de este libro, Gloria Bautista Gutiérrez, actualmente profesora en la Universidad de Clemson (South Caroline, en Estados Unidos), ha publicado hasta ahora muchos ensayos de crítica literaria fijando su especial atención en temas literarios contemporáneos, sobre todo en los narradores hispanoamericanos del siglo XX, como son por ejemplo Gabriel García Márquez, Jorge Luis Borges, Ernesto Sábato, Juan Rulfo, Carlos Fuentes, Isabel Allende y otros. Como resultado de varios años de investigación y enseñanza apareció en 1991 el libro Realismo mágico, cosmos latinoamericano donde la pofesora Bautista vio la necesidad de esclarecer el término "realismo mágico" tan vaga y libremente empleado por muchos críticos literarios hispanoamericanos y europeos a lo largo de nuestro siglo. El mayor valor del libro es el esfuerzo de alumbrar y hacer más comprensible el término mencionado, de concretizar y determinar sus límites formales, tanto en el campo teórico como en el práctico, porque en la segunda parte del libro la teoría se aplica a dos novelas, a Cien años de soledad y a La casa de los espiritus, cuyos autores son escritores muy eminentes, el Nobel colombiano Gabriel García Márquez y la chilena Isabel Allende.

El presente estudio está dividido en la introducción, en tres capítulos centrales y uno aparte donde se enumeran las conclusiones más importantes, en el anexo que es una entrevista de la autora con Isabel Allende y en la bibliografía general como sección obligatoria de cada ensayo crítico.

En la Introducción la autora quiere explicar muy breve y superficialmente el porqué del libro presentando la complejidad del término realismo mágico, su carácter polifacético y la importancia que éste tiene para el discurso narrativo de la literatura del Nuevo Mundo. A continuación se explica la construcción formal de los capítulos siguientes, sobre todo de la tercera sección que elabora un análisis detallado y comparativo de dos novelas, Cien años de soledad y La casa de los espiritus.

El primer capítulo tiene como subtítulo El realismo mágico y está dividido en varios subcapítulos: Historia y conceptualización, El sentido de irrealidad, Teoría y confrontación. Desarollo y controversia, El realismo mágico, lo maravilloso y lo fantástico, ¿Carpentier o Roh? y Aspectos críticos. Primero la autora revela una visión 
histórica mencionando a varios críticos, como por ejemplo Angel Flores, Alejo Carpentier o Enrique Anderson Imbert, que en las décadas de los años cuarenta y de los cincuenta intentaron definir y aclarar el confuso concepto del realismo mágico. Como muestra de la dificultad en la conceptualización adecuada de dicho término, lo que muy bien ha subrayado Gloria Bautista, puede servir el hecho de que hasta ahora no existe una definición clara y unánime que tenga aceptación general, aunque todos más o menos conocemos sus elementos constituyentes. Se remonta también al comienzo del término realismo mágico que curiosamente es una invención europea, es decir volvemos al año 1925 cuando el crítico alemán Franz Roh lo utilizó por primera vaz calificando mágicorrealista la pintura post-expresionista. Con los años y con el aumento de las teorías sobre el realismo mágico, se llega a utilizarlo estrictamente para el discurso narrativo de la literatura hispanoamericana. De este modo se cree que sus elementos fundamentales son el mito, la leyenda y lo fantástico; la realidad se presenta como si fuera mágica o sea el realismo mágico convierte la realidad en fantasía (Seymour Menton); como ejemplos concretos se citan cuentos y novelas de Miguel Angel Asturias y Alejo Carpentier. A este nivel el autor mexicano Fernando Alegría llega a la conclusión de que "el realismo mágico" y "lo real maravilloso" (cuyo teórico, Alejo Carpentier, estableció en sus ensayos toda una teoría sobre su concepto de narrar) son términos sinónimos. Poco a poco, sin embargo, los críticos empiezan a distinguir el realismo mágico, lo real maravilloso y lo fantástico. De este modo Lucila Inés Mena llega a determinar que el realismo mágico y lo fantástico, en realidad, se excluyen mutuamente (los cuentos de Jorge Luis Borges, por ejemplo, se suelen calificar como fantásticos y no mágicorrealistas). Valbuena Briones establece distinción entre lo fantástico y lo mágico. La diferencia es muy clara, o sea lo maravilloso comprende sólo una parte del realismo mágico. Sin embargo, el crítico eminente Jaime Alazraki, por ejemplo, opina que la mejor definición del realismo mágico es la de Alejo Carpentier presentada para su teoría sobre lo real marvilloso.

Después de varias décadas de discusión, el término ha sufrido muchos cambios y transformaciones. Por eso, al final del capítulo, Gloria Bautista trata de sintetizar varias posiciones críticas, definir los temas principales de la concepción mágicorrealista y determinar sus objetivos.

La sección siguiente se divide en cuatro capítulos: Teoria y características, La fe y lo maravilloso, El tiempo mágico y la fe, Características mágicorrealistas. A fuerza de querer esclarecer numerosas dudas alrededor del confuso concepto mágicorrealista, la autora le atribuye clara y distintamente diez características más típicas. Primero intenta eliminar unas confusiones básicas estableciendo las diferencias entre lo mágico y lo fantástico (cita a Tzvetan Todorov y su Introducción a la literatura fantástica) determinando las relaciones entre lo mágico por un lado y lo maravilloso y lo sobrenatural por otro. A pesar de que las características del realismo mágico, presentadas en este libro, son precisas y, dentro de las posibilidades del tema, hasta lo máximo claras, Gloria Bautista admite al final del capítulo que resulta muy difícil establecer los límites de la realidad mágica: «¿Dónde termina la realidad y comienza la magia?» (39). Esta es la dificultad esencial del concepto 
mágicorrealista a la que se deben también en parte numerosas confusiones mostradas ya a partir de la misma aparición del término.

Sigue el último y el más largo capítulo en el que se aplican las definiciones teóricas a dos novelas cuyos autores pertenecen a épocas diferentes dentro de la historia de la narrativa hispanoamericana del siglo XX. Se trata de Gabriel García Márquez e Isabel Allende y sus obras Cien años de soledad y La casa de los espiritus. En la crítica literaria la segunda suele considerarse como un tipo de continuación de la primera, porque también es la saga de una familia, los Trueba, sólo que su relación frente a la realidad histórica y mágica latinoamericana es distinta de la que tiene la histora sobre el destino circular de los Buendía.

El estudio de Cien años de soledad y de La casa de los espiritus conlleva una constante y minuciosa comparación analítica que determina los elementos mágicorrealistas. Gloria Bautista opina que los motivos sobresalientes de estas dos novelas, siguiendo la óptica del realismo mágico, son la soledad, el amor, la muerte, el manejo del tiempo y la caracterización de los personajes. En el análisis detallado de los motivos destacados cabe exponer las opiniones de los filósofos y escritores célebres (como son por ejemplo Platón, Séneca, San Agustín, Leibniz, Kierkegaard, Unamuno, Dante, Montaigne, Camus y muchos más) a las que recurre la autora del libro con el fin de ser más comprensible en su investigación teórico-literaria. Sin embargo, a veces consigue justamente lo contrario. Porque las enumeraciones amontonadas de las interpretaciones filosóficas, dadas sobre un tema por varios pensadores pertenecientes a épocas históricas muy distintas, sólo pueden confundir al lector. Pero a veces estas ilustraciones, siempre muy interesantes, también pueden ser entendidas como apoyo objetivo del análisis de la autora que debe confrontarse con muchas vaguedades procedentes del tema en elaboración.

Los aspectos narrativos, destacados al comienzo del capítulo, se analizan siempre paralelamente en las dos novelas desde el punto de vista mágicorrealista. La conclusión es que las dos obras ofrecen claras diferencias tanto en la conceptualización básica somo en numerosos procedimientos narrativos, pero las unen la estilística del realismo mágico, la preocupación constante y común por el futuro histórico de su continente y una sensibilidad especial proveniente del cosmos maravilloso latinoamericano.

El estudio comparativo de Cien ańos de soledad y de La casa de los espíritus y la contribución al conocimiento más preciso e integrado del concepto mágicorrealista, con la vista histórica sobre el desarrollo del término, representan los dos mayores valores del libro Realismo mágico, cosmos latinoamericano. Este termina con una interesante e informativa entrevista con Isabel Allende donde la autora chilena expresa sus propios pensamientos sobre lo mágico, lo maravilloso, las supersticiones, el papel de la muejr en su narrativa, el feminismo y unos temas más. 